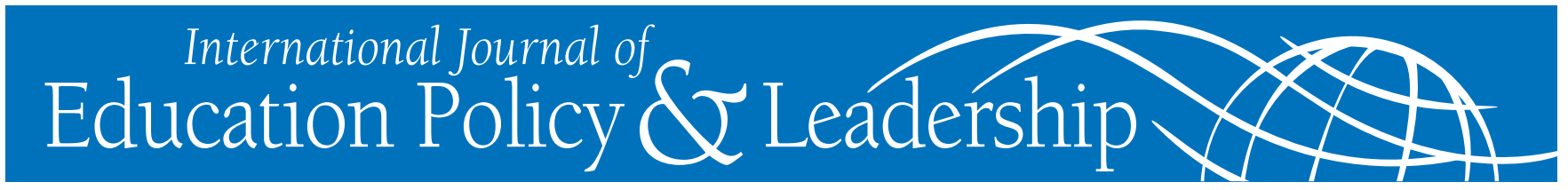

\title{
The Role of Isolation in Predicting New Principals' Burnout ${ }^{1}$
}

\author{
LORAN E STEPHENSON \\ Prince William County Schools \\ SCOTT C BAUER \\ George Mason University
}

\begin{abstract}
Professional isolation has hampered the quality of the work experience for employees in and outside public education for decades. This study explores the role that perceived isolation plays in predicting the quality of the work experience among new principals. The analysis tests whether isolation serves as a mediator in the relationship between factors that are known to affect the quality of work life of principals (social support, role stress, and participation in a structured coaching relationship) and three dimensions of burnout. Regression analysis supports the framework that places isolation as a mediator in predicting physical and emotional burnout, but it does not support this role for cognitive burnout.
\end{abstract}

Bauer, S. C. \& Stephenson, L. (2010). The role of isolation in predicting new principals' burnout. International Journal of Education Policy and Leadership 5(9). Retrieved [date] from www.ijepl.ca.

In recent years, many organizations have paid greater attention to isolation and the impact this factor has on the quality of the employees' work experience (e.g., Brook, Sawyer, \& Rimm-Kaufman, 2007; Bunnell, 2006). Public schools have followed this trend by taking measures to reduce isolation among teachers (e.g., Cookson, 2005; Garmston, 2007). Both the existing literature and the practices of school districts clearly associate better student outcomes with less teacher isolation (e.g., Fullan, 2001; Schlechte, Yssel, \& Merbler, 2005). Less attention has been paid to isolation's impact on principals. Direct treatment of the subject can typically be found in only a handful of books and professional journal articles, which have a tendency to frame isolation primarily as an outcome that reflects the quality of the principals' work environment and make recommendations based almost solely on the conclusions of the teacher isolation literature. The small body of existing literature on principal isolation lacks, for the most part, any direct study of this issue using a systematic research methodology (Beaudoin \& Taylor, 2004; Norton, 2001; Painter, 2000; Schlechte, Yssel, \& Merbler, 2005; Zoul \& Link, 2007). The systematic research studies that do directly address the topic of principal isolation have either assumed it as a negative factor in the life of principals (e.g., Howard $\&$ Mallory, 2008) or only generally established its relationship with principals' perceptions of their own effectiveness (e.g., Dussault \& Thibodeau, 1997).

The evolving role of the principal has garnered increased attention from a variety of different groups, ranging from parents to policymakers, as it has changed over the years from that of a bureaucrat to an instructional leader who takes responsibility for every facet of the school program (Cuban, 1988; Dunklee, 2000). The evolving role of school leaders may have implications in terms of the impact of isolation on principals that goes well beyond anything suggested in

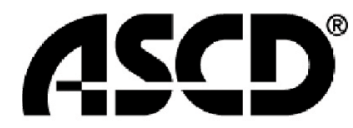

LEARN. TEACH. LEAD.
SIMON FRASER UNIVERSITY THINKING OF THE WORLD

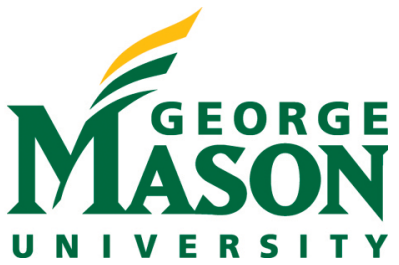


the literature on teacher isolation. For instance, the recent focus on "distributed leadership" emphasizes the fostering, by the principal, of the professional growth of others through frequent interaction, appropriate task delegation, and collaboration as leadership strategies that improve the overall performance of staff and students (e.g., Camburn, Rowan, \& Taylor, 2003; Elmore, 2000; Gronn, 2000; Spillane, Halverson, \& Diamond, 2001). A recent meta-analysis conducted by Robinson, Lloyd, and Rowe (2008) shows that five instructional leadership behaviors have a potent impact on students learning, including promoting and participating in teacher learning. These themes suggest interaction between principals and their fellow educators within the building is vital to the quality and effectiveness of the school and that principal isolation may have a severe impact on leaders' abilities to serve as instructional leaders.

This study seeks to advance scholarship on the topic of isolation by examining the manner in which it directly predicts three dimensions of burnout for new principals and by testing the extent to which isolation mediates the impact of antecedent predictors of the principals' work experience (e.g., coaching, role stress, and social support) on those outcomes. Researchers and policymakers alike have paid greater attention in recent years to the increasing number of new principals joining the ranks of school leaders and the need to better support this growing cross-section of the public education community (Casavant \& Cherkowski, 2001; Daresh, 2004; Hansford \& Ehrich, 2006). In a study involving secondary headteachers in the U.K., Mercer (1996) observed, "It may be that isolation is one factor which is inhibiting individuals from applying for the top post in secondary schools" ( $p$. 176). Focusing on new principals for this work sheds greater light on the needs of this group and may provide a foundation for studying isolation and its impact on principals over the course of their entire careers.

\section{Research Questions}

The research questions for this study focus on investigating the predictive relationship among measures relating to the work experience of new principals; reported levels of isolation; and the emotional, cognitive, and physical burnout they experience. Five variables serve as independent measures related to new principals' work: role ambiguity, role conflict, role overload, social support, and inclusion in a formal coaching program. We follow the analytic procedure spelled out by Baron and Kenny (1986) to use regression analysis to determine if isolation mediates the relationship between these independent variables and the outcome of interest, in this case burnout. Specifically, the threestep analytic process suggests the following questions:

1. What part do role ambiguity, role overload, role conflict, social support, and participation in a formal coaching program play in predicting new principals' isolation?

2. What part do role ambiguity, role overload, role conflict, social support, and participation in a formal coaching program play in predicting new principals' perceptions related to burnout?

3. What part do role ambiguity, role overload, role conflict, social support, participation in a formal coaching program, and isolation play in predicting new principals' perceptions related to burnout?

As Baron and Kenny (1986) suggest, mediation is established if the independent variables affect the mediator (equation one); the independent variables affect the outcome of interest (equation two); and finally, the mediator affects the outcomes of interest when controlling for the effects of the independent variables (equation three). They further specify: "If these conditions all hold in the predicted direction, then the effect of the independent variable on the dependent variable must be less in the third equation than in the second" (p. 1177).

\section{Review of Literature}

The existing literature supports the use of role ambiguity, role conflict, role overload, social support, and participation in a coaching program as predictors of the quality of new principals' work experiences and burnout. It is our hypothesis that isolation serves as a mediator of the relationship between these predictors and outcomes. A review of the relevant literature on isolation for teachers and principals, coupled with a brief look at the research on the other study variables, provides the theoretical foundation for this study. 


\section{Teacher Isolation}

Today, there is little debate about the fact that isolation has a negative impact on the quality of the work experience of teachers (Cookson, 2005; Garmston, 2007; Hord, 2007; McGrail, 2007; Schlechte, Yssel, \& Merbler, 2005). The literature shows a long history of isolation, stemming primarily from the nature of classrooms and the manner in which they are spatially grouped throughout school buildings (Dreeben, 1973; Glickman, Gordon, \& Ross-Gordon, 2004). Lortie's (1975) analogy likening the structure of public school to that of an egg crate accurately captures the way teachers in schools become isolated within their classrooms, despite the fact that they work in close proximity to many of their colleagues.

Historically, the duties affiliated with working in a typical school classroom make it difficult for teachers to perform even a small percentage of their daily responsibilities in collaboration with other professionals, because the majority of their responsibilities lie within individual classrooms (Dreeben, 1973; Glickman, Gordon, \& Ross-Gordon, 2004). The fact that the physical organization and institutional imperatives of schools and classrooms lend themselves to greater teacher isolation sets $\mathrm{K}-12$ education institutions apart from other public and private sector workplaces like hospitals and law firms, which ensure that the majority of the tasks performed by employees occur either in close collaboration with or under the close supervision of others (Glickman, Gordon, \& Ross-Gordon, 2004; Dreeben, 1973).

The physical isolation created by the structure of schools leads to psychological isolation among the teaching staff (Sarason, 1996). The intensive contact teachers have with children, coupled with their lack of regular adult interaction, leads to feelings of loneliness in the professional sphere (Sarason, 1996). These feelings of isolation for teachers then become intensified by the increasing demands of their work (Hargreaves, 1994) and the feeling that they cannot possibly spend enough time with every child to adequately meet their needs (Sarason, 1996). Other accepted norms in today's public schools, like academic freedom and noninterference (Little, 1990; Sindberg \& Lipscomb, 2005), exacerbate the isolation issue further by making the efforts of educators seeking to combat teacher loneliness appear to be restrictive and invasive. All of these factors have a negative impact on the quality of the teachers' work experience that often leads them to implement highly rigid classroom routines as a coping mechanism (Glickman, Gordon, \& Ross-Gordon, 2004).

Isolation for teachers in public schools functions as a complicated variable that both impacts and is impacted by other factors. These trends and evidence provide a theoretical foundation for looking at isolation as more than an outcome or indicator of the quality of the work experience, and they support the decision to position isolation as a factor that acts in concert with other variables to impact the quality of the work experience.

\section{Principal Isolation}

Isolation has become more relevant to principals over time. The administrative demands of schooling have changed drastically since the days of the one-room schoolhouse. Schools have moved from having no principal, to being loosely led by "principal teachers," to having principals who must take full responsibility for all of the administrative and instructional imperatives of the institution (Cuban, 1988; Dunklee, 2000). Nonetheless, principals today tend, like teachers, to make many of their key decisions in isolation.

The literature on the topic of principal isolation continues to be sparse (Beaudoin \& Taylor, 2004; Cookson, 2005; Garmston, 2007; Norton, 2001; Robbins \& Alvy, 2003; Schlechte, Yssel, \& Merbler, 2005). Howard and Mallory's (2008) work supports the inclusion of isolation as a variable that works in concert with the stress created by principal job expectations in the form of role ambiguity, role overload, and role conflict, and Dussault and Thibodeau's (1997) work supports the examination of isolation as a variable that impacts outcomes of the quality of the work experience, such as burnout. A study conducted by Izgar (2009) shows that there is a statistical relationship between measures of principal loneliness and depression. This study extends this literature by testing whether isolation mediates the relationship between key predictors and an outcome reflecting the quality of work life, namely burnout. 


\section{Role Stress}

The three subcategories of role stress (i.e., role ambiguity, role conflict, and role overload) measure the level of stress created by uncertainty about job responsibilities, competing priorities, and work overload. All three forms of role stress appear and function as organizational attributes that contribute to outcomes reflecting the quality of the work experience for professionals in a variety of career sectors (Bunnell, 2006; Conley, Muncey, \& You, 2006; Scheib, 2006; Wong, DeSanctis, \& Staudenmayer, 2007). These variables also serve as important indicators of the organizational and job design of schools and may have particular relevance for the study of new principals. For example, the ever-increasing demands on principals have led to a much greater likelihood that they will experience role ambiguity or overload on a regular basis, particularly when new to the job (Norton, 2003). This evidence supports the use of these subcategories of role stress in this study as a predictor of the quality of the work experience for new principals.

\section{Social Support}

Social support in this study represents the extent to which new principals have opportunities for guidance and support from other professionals within the work environment. Literature involving teachers and professionals in other fields shows that the creation of informal social networks in the workplace that provide support mechanisms, like reassurance of worth and guidance, can reduce stress for individuals who work in contexts and settings like rural communities that tend to isolate employees (Brook, Sawyer, \& RimmKaufman, 2007; Marshall, Michaels, \& Mulki, 2007; Penn et al., 2005; Taylor \& Lee, 2005).

Social support consistently appears in research as an element that improves the quality of the work experience for employees by both enhancing the effect of positive organizational and psychological factors on the job and reducing the impact of negative ones (Brook, Sawyer, \& Rimm-Kaufman, 2007; Marshall, Michaels, \& Mulki, 2007). However, little existing literature empirically analyzes social support and isolation simultaneously as factors that impact work outcomes. The existing evidence, coupled with this lack of guidance about the influence these two variables have on specific work outcomes like burnout, supports the concept of analyzing social support as a separate and distinct variable from isolation and as a predictor of work outcomes for the study principals.

\section{Coaching}

Coaching in this study represents the formal structures that an employer puts in place to ensure that an individual has the skills he or she needs to be productive. Employers use coaching programs to reduce negative factors, like burnout, in the work environment and to improve employee retention (Herrington, Herrington, Kervin, \& Ferry, 2006; Hobson \& Sharp, 2005; Mills, Francis, \& Bonner, 2007). Because coaching programs tend to be treated as interventions designed to improve the performance of new principals, and because participation in such programs is designed both to enhance participants' skills and help them build a network of peers from whom they can learn, this study treats coaching as a contributor to the quality of their work experience and one that may impact both the degree of isolation and the work outcomes we identify in this study.

\section{Burnout}

Burnout, which in this study represents negative physical, emotional, and cognitive job-induced symptoms, is a factor recognized in work environments across a wide variety of settings, including the principal's office (Friedman, 2002; Oplatka, 2002; Tomac \& Tomac, 2008; Vanheule \& Verhaeghe, 2005). Principals who experience lower isolation levels tend also to be less likely to suffer from burnout (Friedman, 2002; Oplatka, 2002; Tomac \& Tomac, 2008; Vanheule \& Verhaeghe, 2005), which in turn increases the chance that they will perform more effectively on the job.

Although the literature has established an isolation-burnout connection for principals, no one has attempted to examine separate manifestations of burnout (i.e., emotional, physical, and cognitive) in a research context involving new principals. This reality, taken in concert with the fact that burnout consistently appears as an outcome variable when analyzed in the context of the principals' work experience quality (Friedman, 2002; Oplatka, 2002; Tomac \& Tomac, 2008; Vanheule \& Verhaeghe, 2005), supports its in- 
clusion in this study as an indicator of the quality of the new principals' job circumstances and its analysis in its aforementioned three manifestations.

\section{Conceptual Framework}

In the framework established for this study, the role stressors, social support, and coaching all serve as predictors of the quality of the new principals' work experience by predicting the principals' levels of emotional, physical, and cognitive burnout. Isolation for new principals functions as a mediator that both predicts burnout and impacts the manner in which the other variables predict these outcomes. Figure 1 provides a visual representation of this framework.

Figure 1. Conceptual Model of the Study Framework
Independent
Mediator
Dependent
Variables
Variables

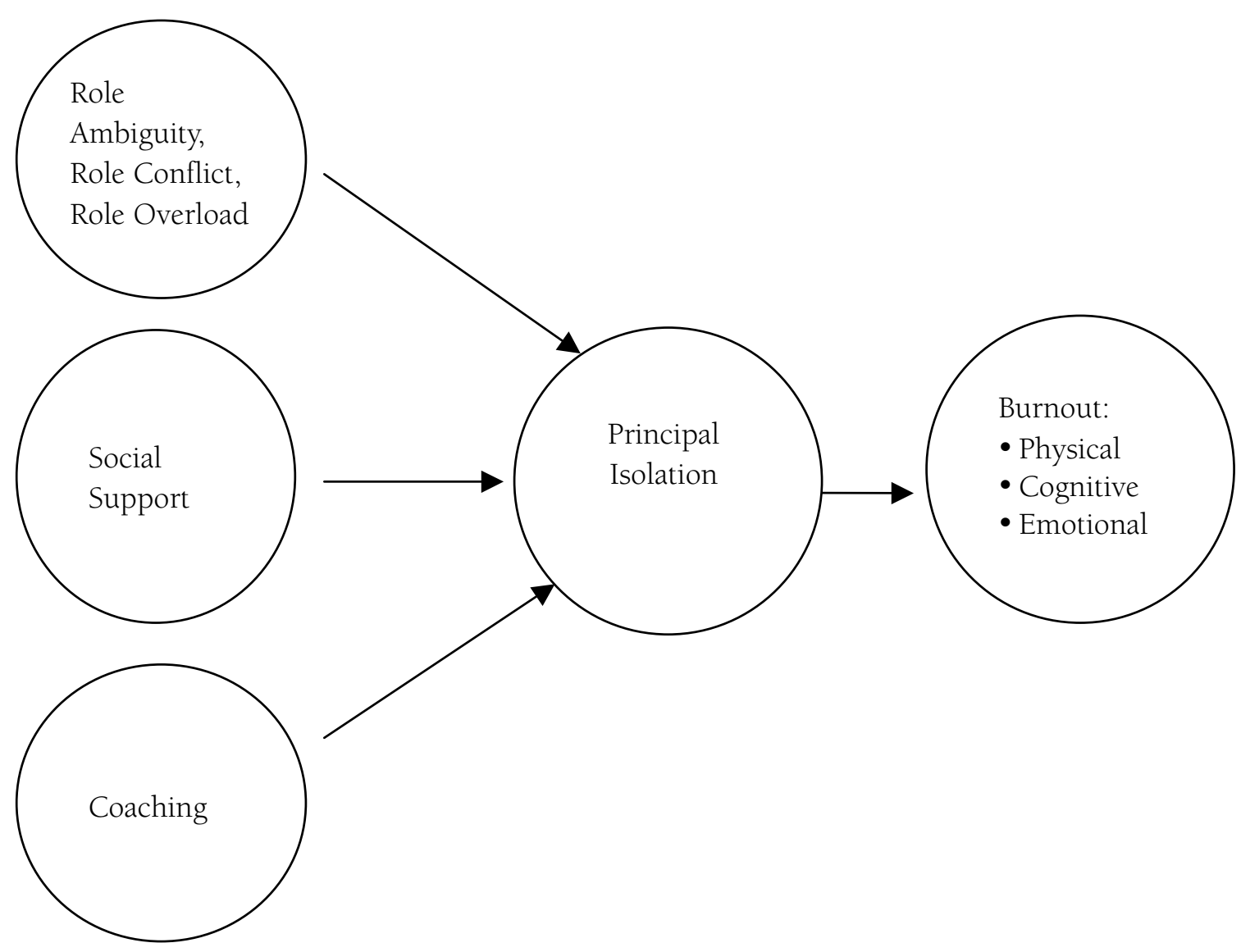

\section{Methods}

\section{Participants and Setting}

This study uses survey data collected from a sample of 196 first- and second-year elementary, middle, high, and alternative school principals from across the state of Louisiana. The data set was collected as part of a larger study examining the impact of instructional coaching on new principals. The principals in this study were selected based on their experience level, as all of them needed to be new principals, and their willingness to participate in the study as either a member of a treatment or comparison group. The treatment group participated in a highly structured coaching program for new principals, while the comparison group did not. All new principals in participating school systems were given the opportunity to be a part 
of the study treatment group. Of these principals, 83 of 85 consented to participate (98 percent response rate). The comparison group consists of all other new principals across the state of Louisiana, and of the 188 of these principals who were invited to participate in the study, 113 principals elected to participate (60 percent response rate).

The principals serve in a variety of demographically different communities, ranging from rural to suburban to urban. The demographic characteristics of the individual principals surveyed for this study represent a wide range of backgrounds:

Gender:

- $\quad$ Male, $n=54$ (28\%)

- Female, $\mathrm{n}=138(72 \%)$

Race:

- African American, $n=73(37 \%)$

- Hispanic, $\mathrm{n}=2$ (1\%)

- White / non-Hispanic, $\mathrm{n}=115$ (59\%)

- Multi-ethnic, $n=3$ (2\%)

Principals included in the study also serve in schools from all levels and from various forms of alternative education:

- Elementary, $\mathrm{n}=118$ (60\%)

- Middle/Junior High, $\mathrm{n}=36$ (18\%)

- High, $\mathrm{n}=34$ (18\%)

- Alternative, $n=6(3 \%)$

- Other, $\mathrm{n}=2(1 \%)$

\section{Measures}

For this study, five survey scales and one treatment group designation provide the data. Each measures one of the major study variables: role stress, social support, coaching, isolation, and burnout.

\section{Role Stress}

This study uses survey items and techniques first pioneered by Rizzo, House, and Lirtzman (1970) to measure perceptions of role conflict and role ambiguity within large organizations (Caldwell \& Forney, 1982; Culbreth, Scarborough, Banks-Johnson, \& Solomon, 2005), and it uses a 17-item instrument based on the measures of Rizzo, House, and Lirtzman (1970), refined by Bacharach and Aiken (1976), and used in Conley, Bacharach, and Bauer (1989) in school settings. The instrument measures three subcategories within the role-stress domain: ambiguity (4 items), conflict (7 items), and overload (6 items). Participants are asked to evaluate each item using a 5-point Likert scale with the response options ranging from "strongly agree" to "strongly disagree," with 1 representing the lowest and 5 the highest degree of role ambiguity, role conflict, or role overload level possible. Higher levels of role stress, in general, are thought to reflect a less desirable work condition for respondents (i.e., higher levels of role ambiguity, role conflict, and role overload reflect a more negative assessment of work life quality).

Questions intended to measure ambiguity focus on aspects of the principals' job that may be confusing or unclear, like the item, "I feel certain about how much authority I have" (an item that would be reverse scored in the four-item scale). Questions intended to measure conflict focus on aspects of the role that may force the participant to deal with competing work conditions or expectations, like the item, "I receive assignments without the manpower to complete them." Questions intended to measure overload focus on parts of the responsibilities of the principal that may lead to feelings of being overwhelmed, like the item, "I seem to have more commitments to overcome than other administrators I know."

\section{Social Support}

The Social Provisions Scale (Cutrona \& Russell, 1987, 1990) has been used by researchers to measure the six social provisions put forth by Weiss (1974), namely attachment, social integration, reassurance of worth, reliable alliance, guidance, and opportunity for nurturance (Bell, 2006; Varvel et al., 2007). This study uses the four latter provisions because of their theoretical connection to the implementation of the coaching process. We selected items that were worded to provide a balance between positively and negatively stated questions. We asked participants to read each of the items and respond with the choice that best reflected their feelings about relationships at work, using a standard five-point Likert scale with options of "strongly agree," "agree," "neutral," "disagree," and "strongly disagree."

Examples of positive survey items on the 16-item scale include, "There are people I can depend on to help me if I really need it" (reliable alliance) and "There is a trustworthy person I could turn to for ad- 
vice if I were having a problem" (guidance). Examples of negatively worded items include, "Other people do not view me as competent" (reassurance of worth) and "There is no one who relies on me for their well-being" (opportunity for nurturance). This study uses the aggregate scale to measure social support. Responses are scored on a scale of 1 to 5 , with 1 representing the lowest and 5 the highest social support level possible. In general, higher levels of social support would be associated with a higher-quality work life.

\section{Coaching}

The principals in the treatment group have been exposed to a highly structured coaching program. The school districts participating in this program hired coaches, usually retired principals, and trained them in a highly structured process that emphasized the use of coaching as a tool to develop instructional leadership skills in new principals. Under this program, coaches met with protégés at least monthly. New principals were required to participate in regular workshops that focused on specific instructional leadership strategies, and they were required to implement an instructional supervision model employing learning walks and a structured feedback strategy to work with teachers to improve pedagogy. They also attended monthly, multidistrict meetings of treatment group participants designed to give greater networking and problemsolving opportunities to its members.

Data for the treatment and comparison groups have been noted using a dummy variable, with participants in the coaching process scored 1 and members of the comparison group scored 0 . Thus, statistical measures of association for this variable reflect the net impact of participation in the treatment.

\section{Isolation}

The UCLA Loneliness Scale has been used for nearly 30 years to measure perceptions of isolation for individuals from a wide variety of backgrounds (Dussault \& Thibodeau, 1997; Izgar, 2009; Russell, Cutrona, de la Mora, \& Wallace, 1997; Russell, Peplau, \& Ferguson, 1978). This study uses a modified version of the most recent form of the UCLA Loneliness Scale (Russell, 1996). The version of the 10-item scale used in this study was modified to adapt it to measure perceptions of isolation in the work setting. For example, a negatively worded statement from version 3 of the
UCLA Loneliness Scale reads, "I lack companionship," while the same item for this study reads, "I lack companionship at work." A positively worded statement from the scale like, "I feel outgoing and friendly" has been modified to read, "At work, I feel outgoing and friendly" for this study.

Participants respond to items in this scale by choosing from the four options of "never," "rarely," "sometimes," or "often," scored on a scale of 1 to 4 , with 1 representing the lowest, and 4 the highest isolation level possible. Thus, higher scores on this scale reflect greater isolation, which would typically be associated with a more negative assessment of the quality of work life.

\section{Burnout}

This study uses a slightly modified form of the Shirom-Melamed Burnout Measure (Shirom, 2003; Shirom \& Melamed, 2006), a 14-item questionnaire to measure three dimensions of burnout: physical fatigue (6 items), emotional exhaustion (3 items), and cognitive weariness ( 5 items). We modified the measure to better reflect the school work setting.

Responses for this iteration of the survey are scored on a scale of 1 to 7 , with 1 representing the lowest, and 7 the highest possible emotional, cognitive, or physical burnout level. Participants read each unique item after pondering the general statement, "Below are statements that describe different feelings you may have at work. Please indicate how often, in the past thirty days, you have felt each of the following ways." This is followed by more specific statements like, "I felt tired" (physical), "I had difficulty concentrating" (cognitive), and "I felt incapable of being sympathetic to others" (emotional).

\section{Analytic Procedures}

Data for this study were collected using an online survey application that allows participants to visit a secure website and complete and submit all answers directly to the research-collecting institution in electronic form. All principals who served as members of the treatment group and as members of the comparison group gave their informed consent before completing and submitting the confidential surveys.

As noted earlier, the research questions for this study focus on clarifying whether isolation serves as a 
mediating factor among role stress, social support, and participation in coaching, as independent variables, and three forms of burnout, as dependent measures. Prior literature associates higher levels of role stress with higher levels of employee burnout (e.g., Bunnell, 2006; Norton, 2003) and higher levels of social support and participation in coaching with lower levels of employee burnout (e.g., Brook, Sawyer, \& RimmKaufman, 2007; Herrington, Herrington, Kervin, \& Ferry, 2006). Although some of the existing principal isolation literature tends to treat the factor primarily as an outcome (e.g., Howard \& Mallory, 2008), other literature suggests that principal isolation contributes to outcomes that reflect the quality of the work experience (e.g., Dussault \& Thibodeau, 1997).

We follow the analytic procedure spelled out by Baron and Kenny (1986) to use regression analysis to determine if isolation mediates the relationship between these independent variables and the outcome of interest, in this case burnout. Mediation is established if the independent variables affect the mediator (step one); the independent variables affect the outcome of interest (step two); and finally, the mediator affects the outcomes of interest when controlling for the effects of the independent variables (step three). The following hypotheses flow logically from the analytic approach, supported by the literature and conceptual framework.

\section{For Step One}

$\mathrm{H}_{1}$ : There will be a statistically significant, positive relationship between the three forms of role stress and isolation.

$\mathrm{H}_{2}$ : There will be a statistically significant, negative relationship between social support and coaching, and isolation.

\section{For Step Two}

$\mathrm{H}_{3}$ : There will be a statistically significant, positive relationship between the three forms of role stress and burnout.

$\mathrm{H}_{4}$ : There will be a statistically significant, negative relationship between social support and coaching, and burnout.

\section{For Step Three}

$\mathrm{H}_{5}$ : Isolation will emerge as a statistically significant, positive predictor of burnout, when controlling for the effects of the independent variables.
To reiterate, results support mediation when the effect of the independent variable on the dependent variable is less in the third equation than in the second.

Statistical significance is reported for each regression model $(p<.05)$. To aid in the interpretation of findings, following Field's (2009) recommendation and computational formula, we also computed an effect size statistic for each regression statistic to represent practical significance. Specifically, Field recommends converting the $t$-statistic to a Pearson correlation ( $r$ ), "because it's widely understood, [and] frequently used" (p. 332) and then using Cohen's (1988) suggestion that a small effect is represented by a correlation of .10, a medium effect a correlation of .30, and a large effect a correlation of .50 .

\section{Limitations}

Although this study yields important analysis and implications for theory-building, research, and practice dealing with the work experience of principals, it has several significant limitations. First, the participants for this study come entirely from one state in the United States of America. This fact may limit the appropriateness of generalizing the results to principals in other states in the United States and overseas. Similar research using a national or even international random sample of principals may help verify these results as they apply to principals across the country and the world.

Second, although nearly years have elapsed since Hurricane Katrina, nonetheless, it is impossible to know how the difficulties and instability created by that calamity may have affected the professional and personal lives of participants and their school systems, and hence their perceptions of factors such as burnout, role stress, and isolation. This factor, too, may limit generalizability.

Finally, the nearly exclusive use of self-reported data in this study will inevitably lead to criticisms about single-source bias (Podsakoff \& Organ, 1986; Spector, 2006). However, the nature of most of the variables in this study cannot be accurately measured by any method other than self-reporting. Most of them are perceptual and psychological by nature and could not be validated by any reliable external measure. Nevertheless, because this study's models are tested 
using single data sources, which may inflate some statistics, the results should be interpreted with due caution.

\section{Results}

Table 1 shows the descriptive statistics for the study variables. In addition, the table displays Cronbach's alpha for scale measures used in the study as an indi- cator of the reliability for this sample. A Cronbach's alpha value of less than .6 represents possible reliability problems with the data collected through one of the instruments. The Cronbach's alpha values ranging from .74 to .95 are consistent with previous studies and provide support for the reliability of the data collection instruments used for this project.

Table 1: Descriptive Statistics for Study Variables

\begin{tabular}{llllllc}
\hline Variable & $N$ & Min. & Max. & Mean & SD & Cronbach's Alpha \\
\hline Role Ambiguity & 194 & 1.00 & 4.75 & 2.04 & 0.63 & .74 \\
Role Conflict & 193 & 1.29 & 5.00 & 2.97 & 0.71 & .83 \\
Role Overload & 193 & 1.40 & 5.00 & 3.44 & 0.70 & .77 \\
Support & 173 & 3.00 & 5.00 & 4.33 & 0.46 & .84 \\
Physical Burnout & 186 & 1.00 & 6.67 & 3.52 & 1.05 & .89 \\
Cognitive Burnout & 186 & 1.00 & 6.00 & 2.97 & 1.01 & .95 \\
Emotional Burnout & 186 & 1.00 & 6.33 & 2.22 & 1.16 & .92 \\
Isolation & 186 & 1.00 & 3.00 & 1.73 & 0.58 & .90 \\
Coaching & 195 & 0.00 & 1.00 & 0.43 & 0.50 & -
\end{tabular}

Descriptive statistics should be considered in the context of the possible score range for each variable. The isolation scale has a score range of 1 to 4; the role ambiguity, role conflict, role overload, and social support,scales all have a score range of 1 to 5; and the physical, emotional, and cognitive burnout scales have a range of 1 to 7 . The descriptive statistics, then, show that the study participants see themselves as having relatively high levels of social support (mean $=4.33$ on a 5-point scale), moderate levels of role conflict and role overload (means $=2.97$ and 3.44, respectively, on a 5-point scale), and moderate levels of burnout. A closer look at the burnout statistics shows that, on average, respondents report higher levels of physical burnout and more moderate levels of cognitive burnout relative to emotional burnout, and that some respondents report very high degrees of burnout, with maximum scores over 6 on a 7 -point scale.

Caution should be taken in interpreting burnout levels. Though scores may seem moderate when taken in the context of the overall range of the scale, even moderate degrees of burnout may still be unacceptably high to many principals and their employers when considering the nature of the phenomena and its asso- ciation with a wide variety of negative personal- and work-related outcomes. This tendency does not appear to translate as strongly to isolation, where mean scores are below 2 and the highest scores do not exceed 3 out of 4 .

Pearson product moment correlations for all of the study variables can be found in Table 2 . Because of the relatively large sample size in this study, the vast majority of the correlations are statistically significant. The number of highly correlated independent variables in this study increases the chances of multicollinearity in regression analyses. Stevens (1996) indicates that the variance inflation factors (VIFs) may be used to gauge the amount of linear association that occurs between a single component and all of the other factors in a regression equation and that, in general, a VIF that exceeds 10 indicates a concerning level of multi-collinearity among variables. Analysis conducted as a part of this study shows that none of the VIF values for any independent variable in this study exceeds a value of approximately 2; hence it does not appear that collinearity represents a significant problem for these results. 
Table 2: Zero-Order Correlations for Variables in Regression Analysis

\begin{tabular}{lccccccccc}
\hline Variable & $\mathrm{v} 1$ & $\mathrm{v} 2$ & $\mathrm{v} 3$ & $\mathrm{v} 4$ & $\mathrm{v} 5$ & $\mathrm{v} 6$ & $\mathrm{v} 7$ & $\mathrm{v} 8$ & $\mathrm{v} 9$ \\
\hline v1 role ambiguity & - & & & & & & & & \\
v2 role conflict & .37 & - & & & & & & & \\
v3 role overload & .41 & .65 & - & & & & & & \\
v4 support & -.29 & -.25 & -.23 & - & & & & & \\
v5 isolation & .40 & .39 & .43 & -.56 & - & & & \\
v6 coaching & -.02 & .03 & .07 & -.13 & .24 & - & & \\
v7 physical burnout & .38 & .38 & .56 & -.21 & .41 & .08 & - & & \\
v8 cognitive burnout & .35 & .30 & .44 & -.23 & .32 & -.02 & .64 & - & \\
v9 emotional burnout & .34 & .32 & .34 & -.46 & .45 & .07 & .48 & .58 & - \\
\hline
\end{tabular}

Note. All zero-order correlations are statistically significant, $\mathrm{p}<.05$, with the exception of those in bold, $\mathrm{p}>.05$.

Results for the step one regression analysis are presented in Table 3. Recall that this step involves testing the relationships between the independent variables and the mediator, isolation. It was hypothesized that there will be a statistically significant, positive relationship among the three forms of role stress and isolation; and that there will be a statistically significant, negative relationship between isolation and the combination of social support and coaching. Table 3 shows a statistically significant relationship between all of the independent variables together and isolation: $R^{2}=.46, F$ $(5,180)=30.86, p<.01$.

The estimates of the regression coefficients show that role ambiguity and role overload are statistically significant predictors of isolation in the hypothesized direction ( $\beta=.16^{*}$ and $\beta=.20^{* *}$, respectively), sug- gesting that higher levels of role stress are associated with greater isolation. Social support serves as the most potent predictor of principal isolation $(B=$ $\left..43^{* *}\right)$, suggesting that greater degrees of social support tend to lessen principal isolation, a finding consistent with expectations. However, participation in the coaching program emerges as a statistically significant predictor $\left(B=.18^{* *}\right)$ in an unexpected fashion, suggesting that principals in the coaching program experience moderately greater degrees of isolation. Effect size computations show social support as having a large effect on isolation $(r=.53)$, with role ambiguity $(r=$ $.18)$, role overload $(r=.19)$, and coaching $(r=.23)$ having small-to-moderate effects. Role conflict fails to emerge as a significant predictor of isolation.

Table 3: Regression Analyses: Independent Variables and Isolation $(\mathbf{n}=186)$

\begin{tabular}{llll}
\hline Variable & $\mathrm{B}(\mathrm{SE})$ & $\beta$ & ES \\
\hline Dependent Variable: Isolation & & & \\
Role Ambiguity & $.15(.06)$ & $.16^{*}$ & .18 \\
Role Conflict & $.07(.06)$ & .08 & .08 \\
Role Overload & $.16(.06)$ & $.20^{* *}$ & .19 \\
Social Support & $-.54(.07)$ & $-.43^{* *}$ & .53 \\
Coaching & $.20(.06)$ & $.18^{* *}$ & .23 \\
$\mathrm{R}^{2}=.46(\mathrm{~F}=30.86, \mathrm{p}<.01)$ & & & \\
\hline
\end{tabular}

The second step in the analytic process involves regressing burnout on the independent variables, shown in Table 4. Three separate equations are presented, one for each type of burnout. We hypothesized that there would be a statistically significant, positive relationship between the three forms of role stress and burn- out and that there would be a statistically significant, negative relationship between the combination of burnout, and social support and coaching. The first equation shows a statistically significant relationship between all of the independent variables and physical burnout: $R^{2}=.34, F(5,180)=18.26, p<.01$. The 
estimates of the regression coefficients show that role ambiguity $\left(\beta=.16^{*}\right)$ and role overload $\left(~\left(\beta=.48^{* *}\right)\right.$ are statistically significant predictors in the expected direction, implying that greater degrees of ambiguity and overload lead to greater degrees of physical burnout. These are the only statistically significant relationships in this equation; thus hypothesis four is not supported. Effect size calculations show that role overload $(r=.39)$ has a medium-to-large effect on physical burnout, and role ambiguity $(r=.16)$ has a small-tomedium effect.

Table 4: Regression Analyses: Independent Variables and Burnout $(\mathbf{n}=186)$

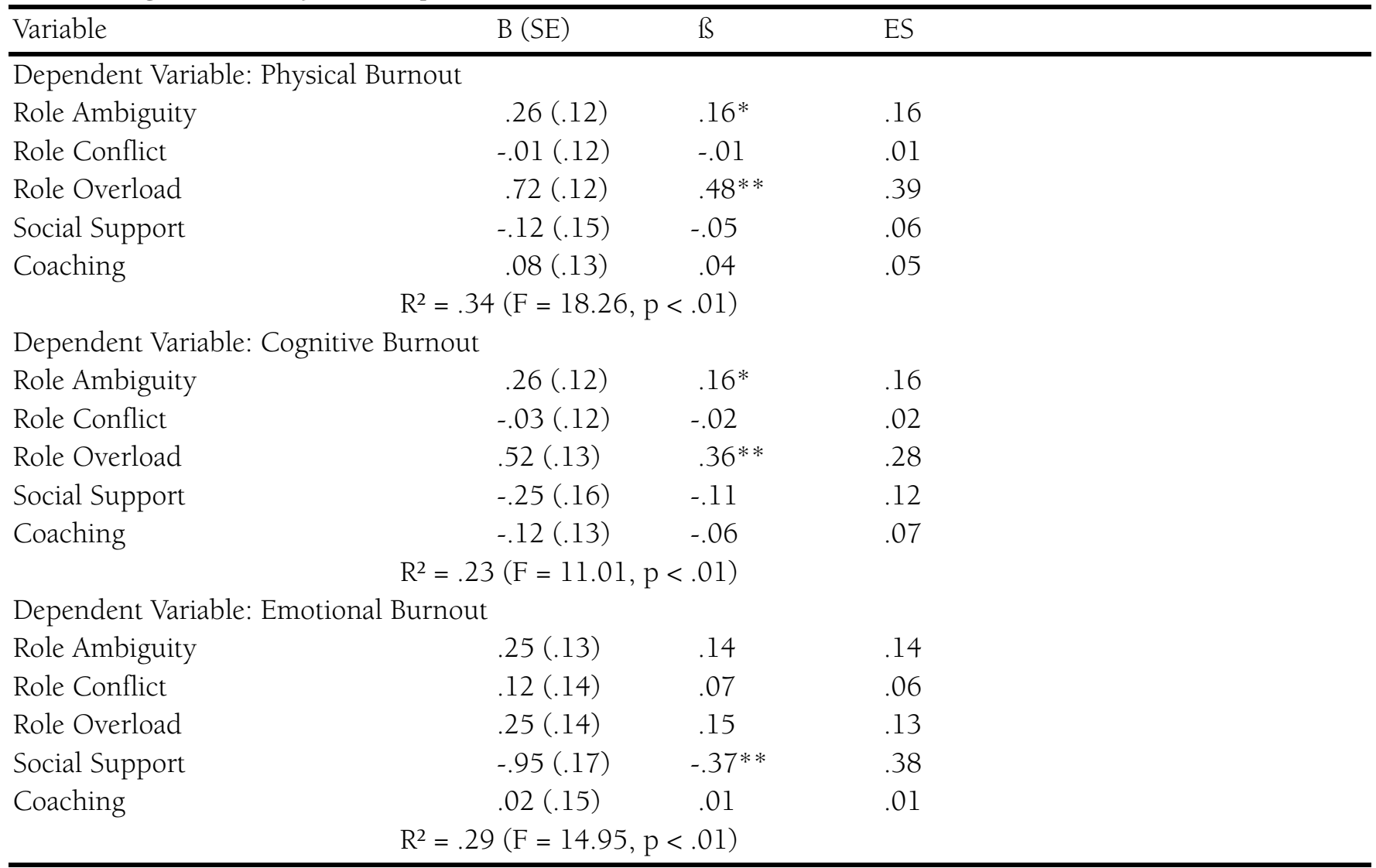

${ }^{*} \mathrm{p}<.05 .{ }^{* *} \mathrm{p}<.01$

The next equation shows a statistically significant relationship between all of the independent variables and cognitive burnout: $R^{2}=.23, F(5,180)=11.01, p$ $<.01$. The estimates of the regression coefficients show the same pattern as the one that emerged with respect to physical burnout: role ambiguity $\left(B=.16^{*}\right)$ and role overload ( $\beta=.36^{* *}$ ) are statistically significant predictors in the expected direction, implying that greater degrees of ambiguity and overload lead to greater degrees of cognitive burnout, and these are the only statistically significant relationships in this equation. Effect size calculations show that role overload $(r=.28)$ has a medium effect on cognitive burnout, and role ambiguity $(r=.16)$ has a small-to-medium effect.
The final equation shows a statistically significant relationship between all of the independent variables and emotional burnout: $R^{2}=.29, F(5,180)=14.95, p$ $<.01$. The estimates of the regression coefficients show that none of the role stress variables emerges as a statistically significant predictor; thus hypothesis three is not supported for this manifestation of burnout. The only statistically significant relationship that emerges in this equation is between social support ( $\left(=-.37^{* *}\right.$ ) and emotional burnout, providing some support for hypothesis four. Effect size calculations show that social support $(r=.38)$ has a medium-to-large effect on emotional burnout and role ambiguity and overload ( $\mathrm{r}$ $=.13$ and .14 ), while not a statistically significant predictors, have a small effect. 
The final step in the analytic process involves investigation of the relationships between the independent variables and the mediator, taken together, and the dependent variables. Hypothesis five stated that we expect isolation to emerge as a statistically significant, positive predictor of burnout, even when controlling for the effects of the independent variables. Further, mediation will be established if the effects of the independent variables on the dependent variable are less in these equations than in the preceding ones. Table 5 presents these results.

Table 5: Regression Analysis: Independent Variables, Isolation, and Burnout ( $\mathrm{n}=186)$

\begin{tabular}{|c|c|c|c|}
\hline Variable & $\mathrm{B}(\mathrm{SE})$ & $\bar{\beta}$ & ES \\
\hline \multicolumn{4}{|c|}{ Dependent Variable: Physical Burnout } \\
\hline Role Ambiguity & $.21(.12)$ & .13 & .13 \\
\hline Role Conflict & $-.04(.12)$ & -.02 & .02 \\
\hline Role Overload & $.66(.13)$ & $.44 * *$ & .37 \\
\hline Social Support & $.07(.17)$ & -.03 & .03 \\
\hline Coaching & $.01(.13)$ & .01 & .01 \\
\hline Isolation & $.35(.15)$ & $.19 *$ & .17 \\
\hline \multicolumn{4}{|c|}{$\mathrm{R}^{2}=.36(\mathrm{~F}=16.53, \mathrm{p}<.01)$} \\
\hline \multicolumn{4}{|c|}{ Dependent Variable: Cognitive burnout } \\
\hline Role Ambiguity & $.23(.12)$ & .14 & .14 \\
\hline Role Conflict & $-.04(.12)$ & -.03 & .03 \\
\hline Role Overload & $.49(.13)$ & $.34 * *$ & .26 \\
\hline Social Support & $-.14(.18)$ & -.06 & .06 \\
\hline Coaching & $-.16(.14)$ & -.08 & .09 \\
\hline Isolation & $.20(.16)$ & .12 & .10 \\
\hline \multicolumn{4}{|c|}{$\mathrm{R}^{2}=.24(\mathrm{~F}=9.49, \mathrm{p}<.01)$} \\
\hline \multicolumn{4}{|c|}{ Dependent Variable: Emotional Burnout } \\
\hline Role Ambiguity & $.20(.13)$ & .11 & .11 \\
\hline Role Conflict & $.09(.13)$ & .06 & .05 \\
\hline Role Overload & $.20(.14)$ & .12 & .10 \\
\hline Social Support & $-.76(.19)$ & $-.30 * *$ & .28 \\
\hline Coaching & $-.05(.15)$ & -.02 & .03 \\
\hline \multirow[t]{2}{*}{ Isolation } & $.34(.17)$ & $.17^{*}$ & .15 \\
\hline & \multicolumn{3}{|c|}{$\mathrm{R}^{2}=.29(\mathrm{~F}=12.80, \mathrm{p}<.01)$} \\
\hline
\end{tabular}

${ }^{*} \mathrm{p}<.05 .{ }^{* *} \mathrm{p}<.01$

The first equation on Table 5 shows a statistically significant relationship among all of the independent variables, isolation, and physical burnout: $R^{2}=.36, F$ $(6,179)=16.53, p<.01$. The estimates of the regression coefficients show that isolation $(~(\beta=.19 *)$ emerges as a statistically significant predictor in the expected direction, suggesting that greater degrees of isolation produce greater levels of physical burnout. Role ambiguity ( $B=.13$ ) is no longer statistically significant, and the impact of role overload ( $B=.44^{* *}$ ) lessens slightly when accounting for the role of isolation in predicting physical burnout. Effect size calculations show that role overload ( $r=.37$ ) continues to have a medium-tolarge effect on physical burnout and isolation $(r=.17)$ has a small-to-medium effect. Thus, for this type of burnout, there is some support for isolation as a mediator.

The next equation shows a statistically significant relationship among all of the independent variables, isolation, and cognitive burnout: $R^{2}=.24, F(6,179)=$ $9.49, p<.01$. The estimates of the regression coefficients show that isolation ( $B=.12$ ) fails to emerge as a statistically significant predictor. Role ambiguity ( $B=$ .14) is no longer statistically significant when account- 
ing for the added influence of isolation, and the impact of role overload ( $B=.34^{* *}$ ) lessens slightly when accounting for the role of isolation in predicting physical burnout. Effect size calculations show that role overload $(r=.26)$ has a medium effect on physical burnout. For this type of burnout, then, there is scant support for isolation as a mediator.

The final equation, dealing with emotional burnout, shows a statistically significant relationship among all of the independent variables, isolation, and emotional burnout: $R^{2}=.29, F(6,179)=12.80, p<.01$. The estimates of the regression coefficients show that isolation ( $\left(=.17^{*}\right)$ emerges as a statistically significant predictor in the expected direction, suggesting that greater degrees of isolation produce greater levels of emotional burnout. The impact of social support ( $B=-$ $.30 * *)$, the only other statistically significant predictor, lessens when accounting for the role of isolation in predicting emotional burnout. Effect size calculations show that social support $(r=.28)$ continues to have a medium effect on this type of burnout, while isolation $(r=.15)$ has a small-to-medium effect. For this type of burnout, there is some support for isolation as a mediator.

\section{Discussion}

This study's purpose centers on the idea of establishing, through systematic analysis, actionable information about the relationship between isolation and outcomes of the quality of the work experience for new principals. Our goal was two-fold: First, given the paucity of empirical work on principal isolation, we sought to add to what is known about the role of isolation in predicting an important work outcome, burnout. Second, by testing the mediation model, we sought to help elaborate existing theory relating to understanding how isolation impacts the work life of principals.

In summation, analyses show that isolation is predicted by two forms of role stress (ambiguity and overload) and social support in an expected direction. Participation in a coaching program also emerged as a statistically significant predictor, though in an unexpected fashion, suggesting that being involved in coaching exacerbates the degree of isolation at work. Analyses then show that isolation serves as a statistically significant predictor of two manifestations of burnout, physical and emotional, even when accounting for factors widely studied as indicators of the quality of work life. The three-step analysis suggests that there is some support for the role of isolation as a mediator of the relationship between at least some of these independent variables and perceived burnout of new principals.

The findings of this study raise interesting questions for researchers, policymakers, and practitioners who seek to improve the quality of the new principals' work experience. A brief look at the implications of these results for practice and research reveals the need for additional exploration of the principal isolation issue in both the scholarly and professional realms.

Based on these analyses, it appears that reducing new principal burnout should involve attending to issues related to role overload and social support, which directly impact all three types of burnout and isolation, and to a lesser extent factors relating to role ambiguity and isolation. Attending to these factors presents significant implementation challenges for school systems. To the extent that isolation reflects principals' sense of separation from individuals who serve in similar roles and experience the same challenges they do in their jobs, the structure of most school districts at the principal level mirrors the eggcrate makeup seen within school buildings. If the fostering of additional collaboration and social support has been a challenge for schools to achieve for teachers who work in the same building, then it will likely be even more difficult to create for principals who work miles apart from one another. This research also supports the idea of principal workload reduction, which also seems problematic in the face of the limited financial and human resources with which most schools and divisions must cope.

Donaldson's (2006) observations seem to capture our findings well. He notes that principals are sometimes isolated from student learning and the work of teachers because of managerial demands: "Principals are frequently so inundated with short-term demands and problems that their work lives become governed by management tasks and decisions" (p. 99), leading to a kind of goal displacement that relegates long-term, education successes to a subordinate position with completing administrative tasks. This may be especially true for new principals, who spend a significant amount of their time learning the administrative ropes. 
This reality helps explain the importance of factors like role overload and role ambiguity and the perverse effect of involvement in the coaching process. The coaching model used for new principals in this study is highly structured and demands a great deal of time and attention to instructional supervision. In the face of negotiating the managerial demands of a new and very demanding role, this may be seen as just another drain on time and energy needed to complete other tasks.

Fullan (2001), among others, calls for school leaders to work to create professional learning communities, collaborative cultures that focus on the improvement of student—and adult-learning in schools. In a synthesis of the research, Robinson, Lloyd, and Rowe (2008) observe that one of the most potent leadership behaviors that produces significant improvements in student learning is "promoting and participating in teacher learning and development" (p. 663). In many schools, though, the reality seems to be that professional learning communities are viewed as something principals enable for teachers but do not participate in themselves, and actually participating in teacher learning and development is out of the question given the managerial demands of the job. In reality, influencing factors like social support and workload for new principals may require school systems to make some fundamental changes to the concept of the principalship, allowing for a restructuring of expectations and the priority with which resources are allotted. Just providing a coaching or mentoring program may be perceived as an onus rather than a help.

In summation, this work has important implications for those seeking to explore the issue of isolation and its impact on school principals, providing direction and additional theory for future exploration of this topic. First, this study recognizes and validates the idea that isolation exists in the lives of new principals as a complicated variable that impacts and is impacted by other work environment factors, and it provides some support for the treatment of isolation as a mediator. Second, this research shows that isolation significantly impacts physical and emotional burnout, important outcomes of the quality of work life of new principals, which gives researchers a clear rationale for future examination of this issue in relation to other factors associated with quality of work life and additional work outcomes, such as job satisfaction or in- tent to leave. It is our hope that this investigation both informs practice and prompts future research.

1. Note: Data for this study is a subset of the data compiled for U.S. Department of Education Award \#R305E50082, The Coaching Model: A Collaborative Pilot Program. The authors would like to gratefully acknowledge the support of the School Leadership Center of Greater New Orleans, the recipient of the grant, and the U.S. Department of Education's Institute of Education Sciences National Center for Education Research. The authors take sole responsibility for the work presented.

\section{References}

Bacharach, S. B., \& Aiken, M. (1976). Structural and process constraints on influence in organizations: A level-specific analysis. Administrative Science Quarterly, 21(4), 623-642. doi:10.2307/2391720

Baron, R. M., \& Kenny, D. A. (1986). The moderatormediator variable distinction in social psychological research: Conceptual, strategic, and statistical considerations. Journal of Personality and Social Psychology, 51, 1173-1182.

Beaudoin, M., \& Taylor, M. E. (2004). Creating a positive school culture: How principals and teachers can solve problems together. Thousand Oaks, CA: Corwin Press.

Bell, B. (2006). Wilderness orientation: Exploring the relationship between college preorientation programs and social support. Journal of Experiential Education, 29, 145-168.

Brook, L., Sawyer, E., \& Rimm-Kaufman, S. E. (2007). Teacher collaboration in the context of the responsive classroom. Teachers and Teaching, 13, 211.

Bunnell, T. (2006). Managing the role stress of public relations practitioners in international schools. Educational Management Administration \& Leadership, 34(3), 385-409. doi:10.1177/1741143206065271

Caldwell, W., \& Forney, J. (1982). The relationship of role conflict and ambiguity and perceived organizational characteristics between superintendents and principals. New York: American Educational Research Association. Retrieved from ERIC database. (ED218770) 
Camburn, E., Rowan, B., \& Taylor, J. E. (2003). Distributed leadership in schools: The case of elementary schools adopting comprehensive school reform models. Educational Evaluation and Policy Analysis, 25(4), 347-373. doi:10.3102/01623737025004347

Casavant, M. D., \& Cherkowski, S. (2001). Effective leadership: Bringing mentoring and creativity to the principalship. NASSP Bulletin, 85(624), 71-81. doi:10.1177/019263650108562409

Cohen, J. (1988). Statistical power analysis for the behavioral sciences. Mahwah, NJ: Lawrence Erlbaum.

Conley, S. C., Bacharach, S. B., \& Bauer, S. (1989). The school work environment and teacher career dissatisfaction. Educational Administration Quarterly, 25(1), 58-81. doi:10.1177/0013161X89025001004

Conley, S. C., Muncey, D. E., \& You, S. (2006) Standards-based evaluation and teacher career satisfaction: A structural equation modeling analysis. Journal of Personnel Evaluation in Education, 18, 3965.

Cookson, P. W. (2005). The challenge of isolation: Professional development-your first year. Teaching Pre K-8, 36, 14.

Cuban, L. (1988). The managerial imperative and the practice of leadership in schools. Albany, NY: SUNY Press.

Culbreth, J., Scarborough, J., Banks-Johnson, A., \& Solomon, S. (2005). Role stress among practicing school counselors. Counselor Education and Supervision, 45, 58-71.

Cutrona, C., \& Russell, D. (1987). The provisions of social relationships and adaptation to stress. In. W. Jones and D. Perlman (Eds.), Advances in personal relationships (Vol. 1, pp. 37-67). Greenwich, CT: JAI Press.

Cutrona, C., \& Russell, D. (1990). Type of social support and specific stress: Toward a theory of optimal matching. In I. G. Sarason, B. R. Sarason, \& G. Pierce (Eds.), Social support: An interactional view (pp. 319-366). New York: Wiley.

Daresh, J. (2004). Mentoring school leaders: Professional promise or predictable problems? Educational Administration Quarterly, 40(4), 495-517. doi:10.1177/0013161X04267114
Donaldson, G. (2006). Cultivating leadership in schools: Connecting people, purpose, and programs (2nd ed.). New York: Teachers College Press. Dreeben, R. (1973). The school as a workplace. In R. M. Travers (Ed.), Second handbook of research on teaching. Chicago: Rand McNally.

Dunklee, D. (2000). If you want to lead, not just manage: A primer for principals. Thousand Oaks, CA: Corwin.

Dussault, M., \& Thibodeau, S. (1997). Isolation and performance at work of school principals. Journal of School Leadership, 7(5), 521-536.

Elmore, R. F. (2000). Building a new structure for school leadership. Washington, DC: The Albert Shanker Institute.

Field, A. (2009). Discovering statistics using SPSS, $3^{\text {rd }}$ ed. Los Angeles: Sage.

Friedman, I. A. (2002). Burnout in school principals: Role related antecedents. Social Psychology of Education, 5(3), 229-251. doi:10.1023/A:1016321210858

Fullan, M. (2001). Leading in a culture of change. San Francisco: Jossey-Bass.

Garmston, R. (2007). Collaborative culture. Journal of Staff Development, 28(2), 55-57.

Glickman, C. D., Gordon, S. P., \& Ross-Gordon, J. M. (2004). Supervision and Instructional Leadership. Boston: Allyn and Bacon.

Gronn, P. (2000). Distributed properties: A new architecture for leadership. Educational Management Administration \& Leadership, 28(3), 317-338. doi:10.1177/0263211X000283006

Hansford, B., \& Ehrich, L. C. (2006). The principalship: How significant is mentoring? Journal of Educational Administration, 44(1), 36-52. doi:10.1108/09578230610642647

Hargreaves, A. (1994). Changing teachers, changing times: Teacher work and culture in the postmodern age. London: Cassel.

Herrington, A., Herrington, J., Kervin, L., \& Ferry, B. (2006). The design of an online community of practice for beginning teachers. Contemporary Issues in Technology and Teacher Education, 6, 120132.

Hobson, A. J., \& Sharp, C. (2005). Head to head: A systematic review of the research evidence on mentoring new head teachers. School Leadership and Management, 25, 25-42. 
Hord, S. M. (2007). Learn in community with others. Journal of Staff Development, 28, 39-42.

Howard, M. P., \& Mallory, B. J. (2008). Perceptions of isolation among high school principals. Journal of Women in Education Leadership, 6, 7-27.

Izgar, H. (2009). An investigation of depression and loneliness among school principals. Educational Sciences: Theory \& Practice, 9, 247-258.

Little, J. W. (1990). The persistence of privacy: Autonomy and initiative in teachers' professional relations. Teachers College Record, 91, 509-536.

Lortie, D. (1975). Schoolteacher: A sociological study. Chicago: University of Chicago Press.

Marshall, G. W., Michaels, C. E., \& Mulki, J. P. (2007). Workplace isolation: Exploring the construct and its measurement. Psychology and Marketing, 24(3), 195-223. doi:10.1002/mar.20158

McGrail, E. (2007). Laptop technology and pedagogy in the English language arts classroom. Journal of Technology and Teacher Education, 15(1), 59-85.

Mercer, D. (1996). 'Can they walk on water?' Professional isolation and the secondary headteacher. School Organisation, 16(2), 165-178. doi:10.1080/02601369650037967

Mills, J., Francis, K., \& Bonner, A. (2007). The problem of workforce for the social world of Australian rural nurses: A collective action frame analysis. Journal of Nursing Management, 15(7), 721-730. doi:10.1111/j.1365-2934.2006.00738.x

Norton, J. (2001). Sharing the mystery. Journal of Staff Development, 22(1), 51-54.

Norton, M. (2003). Let's keep our quality school principals on the job. High School Journal, 86(2), 5056.

Oplatka, I. (2002). Women principals and the concept of burnout: An alternative voice? International Journal of Leadership in Education, 5(3), 211-226.

Painter, S. R. (2000). Principals' perceptions of barriers to teacher dismissal. Journal of Personnel Evaluation in Education, 14(3), 253-264. doi:10.1023/A:1008144215978

Penn, D. L., Simpson, L., Gavin, E., Leggett, S., Wood, L., Hawgood, J., et al. (2005). Development of ACROSSnet: An online support system for rural and remote community suicide prevention workers in Queensland, Australia. Health Informatics Journal, 11(4), 275-293. doi:10.1177/1460458205058755
Podsakoff, P. M., \& Organ, D. W. (1986). Self-reports in organizational research: Problems and prospects. Journal of Management, 12(4), 531-544.

Rizzo, J. R., House, R. J., \& Lirtzman, S. I. (1970). Role conflict and ambiguity in complex organizations. Administrative Science Quarterly, 15(2), 150-163. doi:10.2307/2391486

Robbins, P., \& Alvy, H. B. (2003). The principal's companion: Strategies and hints to make the job easier. Thousand Oaks, CA: Corwin Press.

Robinson, V. M., Lloyd, C. A., \& Rowe, K. J. (2008).

The impact of leadership on student outcomes: An analysis of the differential effects of leadership types. Educational Administration Quarterly, 44(5), 635-674. doi:10.1177/0013161X08321509

Russell, D. (1996). The UCLA Loneliness Scale (Version 3): Reliability, validity, and factor structure. Journal of Personality Assessment, 66(1), 20-40. doi:10.1207/s15327752jpa6601_2

Russell, D., Cutrona, C. E., de la Mora, A., \& Wallace, R. B. (1997). Loneliness and nursing home admission among the rural older adults. Psychology and Aging, 12(4), 574-589. doi:10.1037/08827974.12.4.574

Russell, D., Peplau, L. A., \& Ferguson, M. L. (1978). Developing a measure of loneliness. Journal of Personality Assessment, 42(3), 290-294. doi:10.1207/s15327752jpa4203_11

Sarason, S. B. (1996). Revisiting the culture of the school and the problem of change. New York: Teachers College Press.

Scheib, J. (2006). Policy implications for teacher retention: Meeting the needs of the dual identities of arts educators. Arts Education Policy Review, 107(6), 5-10. doi:10.3200/AEPR. 107.6.5-10

Schlechte, J., Yssel, N., \& Merbler, J. (2005). Pathways to burnout: Case studies in teacher isolation and alienation. Preventing School Failure, 50(1), 35. doi:10.3200/PSFL.50.1.35-40

Shirom, A. (2003). Job-related burnout. In J. C. Quick \& L. E. Tetrick (Eds.), Handbook of occupational health psychology (pp. 245-265). Washington, DC: American Psychological Association.

Shirom, A., \& Melamed, S. (2006). A comparison of the construct validity of two burnout measures in two groups of professionals. International Journal of Stress Management, 13(2), 176-200. doi:10.1037/1072-5245.13.2.176 
Sindberg, L., \& Lipscomb, S. D. (2005). Isolation and the public school music teacher. Bulletin of the Council for Research in Music Education, 166, 4356.

Spector, P. E. (2006). Method variance as an artifact in self-report affect and perceptions at work: Myth of significant problem? Journal of Applied Psychology, 72, 438-444.

Spillane, J. P., Halverson, R., \& Diamond, J. B. (2001). Investigating school leadership practice: A distributed perspective. Educational Researcher, 30(3), 23-28. doi:10.3102/0013189X030003023

Stevens, J. (1996). Applied multivariate statistics for the social sciences (3rd ed.). Mahwah, NJ: Lawrence.

Taylor, R., \& Lee, H. (2005). Occupational therapists' perception of usage of information and communication technology (ICT) in western Australia and the association of availability of ICT on recruitment and retention of therapists working in rural areas. Australian Occupational Therapy Journal, 52(1), 51-56. doi:10.1111/j.1440-1630.2005.00461.x

Tomac, W., \& Tomac, E. (2008). Existential fulfillment and burnout among teachers and principals. Journal of Beliefs and Values, 29, 11-27.
Vanheule, S., \& Verhaeghe, (2005). Professional burnout in the mirror: A qualitative study from a Lacanian perspective. Psychoanalytic Psychology, 22(2), 285-305. doi:10.1037/0736-9735.22.2.285

Varvel, S., He, Y., Shannon, J., Tager, D., Bledman, R., Chaichanasakul, A., et al. (2007). Multidimensional, threshold effects of social support in firefighters: Is more support invariably better? Journal of Counseling Psychology, 54(4), 458-465. doi:10.1037/0022-0167.54.4.458

Weiss, R. S. (1974). The provisions of social relationships. In Z. Rubin (Ed.), Doing unto others. Englewood Cliffs, NJ: Prentice-Hall.

Wong, S., DeSanctis, G., \& Staudenmayer, N. (2007). The relationship between task interdependency and role stress: A revisit of the job demands-control model. Journal of Management Studies, 44(2), 284-303. doi:10.1111/j.1467-6486.2007.00689.x

Zoul, J., \& Link, L. (2007). Cornerstones of strong schools: Practices for purposeful leadership. Larchmont, NY: Eye on Education.

IJEPL is a joint publication of the Association for Supervision and Curriculum Development, the Faculty of Education at Simon Fraser University, and the College of Education and Human Development at George Mason University. By virtue of their appearance in this open access journal, articles are free to use, with proper attribution, in educational and other non-commercial settings 90 days after initial publication. Copyright for articles published in IJEPL is retained by the authors. More information is available on the IJEPL Web site: http://www.ijepl.org 